\title{
Maintaining an active lifestyle is always good
}

\author{
Magdy Hassouna, MD, PhD, FRCSC, FACS
}

See related article on page 180.

7 he current manuscript by Santa Mina and colleagues ${ }^{1}$ evaluated the effect of physical activity on the healthrelated quality of life experienced by prostate cancer patients following radical prostatectomy.

The study followed a group of 60 patients who underwent such surgery. The authors conducted several questionnaires and appraisals of physical fitness prior to surgery and assessed patient health-related quality of life afterwards. The study was successful in determining those effects.

It was thus concluded that physical activity is a useful intervention in preventing lengthy postoperative hospitalization and limiting disability and complications during recovery. The findings further strengthen the already growing scholarly support for acknowledging the importance of promoting a physically active lifestyle in all age groups. Their preventive effects provide a beneficial measure of improving the quality of life for patients undergoing radical surgeries.

Any amount of physical activity is encouraged and should not be delayed until prostate cancer rears its ugly head.
Professor of Surgery (Urology)P, University of Toronto, Toronto, ON

Competing interests: None declared.

This paper has been peer-reviewed.

\section{Reference}

1. Santa Mina D, Matthew AG, Trachtenberg J, et al. Physical activity and quality of life after radical prostatectomy. Can Urol Assoc J 2010;4:180-6.

Correspondence: Dr. Magdy Hassouna, Toronto Western Hospital, McLaughlin Pavilion, 11th Floor, Room 11MCL433, 399 Bathurst St., Toronto, ON; fax: 416-603-1961; magdy.hassouna@uhn.on.ca 